\title{
Contribuições da Hygiene à escolarização da Educação Física
}

Fernanda Simone Lopes de Paiva*

\begin{abstract}
Resumo: Explora parte da argumentação construída por Paiva (2003) na demonstração da centralidade do processo de escolarização na criação das condições de possibilidade para o engendramento do campo da educação física no Brasil. Apresenta, categoriza e analisa representações e práticas médico-higienistas veiculadas na produção do conhecimento sobre e para a educação physica, tendo como fontes as theses sustentadas na Faculdade de Medicina do Rio de Janeiro, no século XIX.

Palavras-chave: Pensamento Médico-higienista Oitocentista, História da Educação Física no Brasil, Escolarização.
\end{abstract}

Em estudo desenvolvido anteriormente (PAIVA, 2003) busquei demonstrar a tese de que se a educação física hodierna é tributária do pensamento higienista desenvolvido no Brasil do século XIX, esse tributo se alavanca no processo de escolarização ${ }^{l}$ da educação física projetado - o que não significa cumprido neste tempo e lugar - pelos médicos formados pela Faculdade de Medicina do Rio de Janeiro (FMRJ) e não em um processo de biologização, ${ }^{2}$ como

* Doutora em Educacão pela FaE/UFMG. Pesquisadora do Laboratório de Estudos em Educação Física - LESEF - do CEFD/UFES

1 A literatura da área de educação tem entendido escolarização em, pelo menos, três sentidos, a saber: a) como processo de extensão da escola a um número cada vez maior de sujeitos, b) como processo de produção de referências sociais que tem como base a escola (FARIA FILHO, 2000) e c) como processo de transformação de conhecimentos sociais e científicos em conhecimentos escolares, tal como propõe Chervel (1992). Esta pesquisa captou ementosque permitem pensá- ta principalmente Chervel (1092). Esta pesquisa captou "le "c".

2 A tendência à biologização da educação física foi caracterizada no processo de redução do estudo "do Homem em Movimento apenas a seu aspecto biológico [...]. Tal 'reducionismo biológico' configura-se [hoje] na ênfase [...] às questões afetas à performance desportiva, à correspondente na Educação Física, à ordem de produtividade, eficiência e eficácia, inerente ao modelo de sociedade [capitalista]. [A tendência à biologização] reflete [...] a presença sempre marcante da categoria médica na Educação Física em nosso país. Percebe saúde somente nos seus aspectos biofisiológicos.." (CASTELLANI FILHO, 1988, p. 218). A presença sempre aspectos biofisiologicos..." (CASTELLANI FILHO, 1988, p. 218). A presença sempre marcante dos médicos na area, dar-se-ia, desde o século XIX, quando a educação física "foi entendida como um elemento de extrema importância para o forja daquele indivíduo 'forte', 'saudável', indispensável à implementação do processo

Movimento, Porto Alegre, v. 10, n. 3, p.53-75, setembro/dezembro de 2004 
insinuado por Castellani Filho (1988), pulverizado e absorvido, sem problematização e aprofundamento, pelo senso comum acadêmico da educação física.

A questão central que orientou aquela pesquisa foi identificar e analisar de que "formas" se investiram as práticas e representações no campo médico cunhando sentidos para a educação physica e as maneiras como foram negociadas, a partir dessas práticas, representações e conseqüentes (re)apropriações, as condições de troca comunicativa (cedência, empréstimo, imposição) com outras esferas de produção de sentido, tais como o Estado e a escola. Essa questão foi desdobrada em três: a) decifrar como os médicos produziram sua autoridade para si e para os outros para arbitrar questões afetas à educação (physica), b) argüir a que eles se referiam quando falavam em educação física e c) rastrear, indiciariamente, a circulação e apropriação dessas representações e práticas forjadas no nascente âmbito escolar do Brasil oitocentista.

O presente artigo explora, em parte, o segundo desdobramento da questão central, apresentando, categorizando e analisando as práticas e representações médico-higienistas veiculadas na produção do conhecimento sobre e para a educação physica, tendo como fontes as theses sustentadas na FMRJ, no século XIX. Dois esclarecimentos teórico-metodológicos fazem-se necessários. O primeiro deles explicita a escolha das fontes e sua periodização. O segundo, o tratamento dado a elas.

de desenvolvimento do país..." (CASTELLANI FILHO, 1988, p. 39). Médicos (e militares) teriam investido no entendimento que associava educação física à educação do físico e a um determinado tipo de saúde corporal visando a criação do "corpo saudável, robusto e harmonioso organicamente [...] em oposição ao corpo relapso, flácido e doentio do indivíduo colonial..." (CASTELLANI FILHO, 1988, p. 43). Assim, é possível entender que o autor considera que os médicos, desde o século XIX, e possivel entender que o autor considera que os medicos, desde o seculo XIX, teriam deflagrado um processo de biologização da educação física, sempre
operando com um conceito restrito de saúde - biológica.

3 Esse senso comum foi mapeado nas coletâneas de textos dos Encontros de História da Educação Física, Esporte, Lazer e Dança e nos anais dos Congressos Brasileiros de Ciências do Esporte (PAIVA, 2003).

4 Tentando diferenciar sentidos para um mesmo termo, grafo educação física para o sentido hodierno de disciplina escolar e acadêmica, educação physica para o sentido genérico de educação tal foi entendida no projeto de educação integral e "educação física", entre aspas, para designar quando o termo é usado de forma
indeterminada, ambígua ou confusa. indeterminada, ambígua ou confusa.

5 Caberia, ainda, um terceiro comentário sobre como as séries documentais foram construídas e a primeira aproximação feita pautada na cronologia. Por questão de espaço, remeto o leitor a Paiva (2003).

Movimento, Porto Alegre, v. 10, n. 3, p.53-75, setembro/dezembro de 2004 
As theses se mostraram uma fonte fecunda porque permitiram agudizar as relações estabelecidas entre o pensamento médico e a educação física no Brasil por meio do mapeamento e da análise dos sentidos produzidos em torno da e na educação física. Seu legado foi então enfocado nas trocas simbólicas, nas quais observei continuidades e inflexões permeando a produção de sua especificidade.

A leitura do Catálogo de Teses (1832-1985) da Faculdade de Medicina da UFRJ provocou o registro das primeiras observações e dúvidas. Mapeados, os títulos das theses sugeriam um desenho que tornava patente reordenações no desenvolvimento da produção do conhecimento médico naqueles mais de 150 anos. Sobre educação física - e temas afins - nada encontrei após 1928. Assim, o corpus documental inicial ia do aparecimento ao momento em que os médicos se calavam sobre a temática estudada. A idéia inicial era trabalhar com esse conjunto. Entretanto, uma primeira leitura impôs um novo recorte temporal. As theses escritas no século XX sinalizaram para uma dispersão de abordagens e uma complexificação do debate que exigiria, por si só, um estudo específico. Por um lado, estudos em história da medicina apontam uma reordenação específica no campo médico no início do século XX; por outro, não me pareceu uma questão a ser menosprezada o fato de as theses não acompanharem o fervor com o qual os médicos se inseriam na discussão educacional em outros fóruns, como os congressos de higiene, por exemplo. Deste modo, o critério para o recorte temporal final foi, então, a antevisão de uma unidade na diversidade: no século XIX os médicos pensaram a educação física de diferentes formas (diversidade), entretanto, reconheciam (unidade) que esta era-lhes uma questão obrigatória (BOURDIEU, 1987) sobre a qual debateram em todas as suas instâncias de consagração.

No que diz respeito ao tratamento das fontes como objeto, é preciso marcar que não desconheço a existência de pesquisadores que desqualificam as theses como fonte documental, alegando falta de impacto e imaturidade de seus autores; falta de originalidade, considerando que as compilações eram freqüentes a época; além de falta de "cientificidade", representativos do conhecimento médico então acumulado. Seriam, em síntese, trabalhos "...comunicando apenas convicções de época ou idéias difusas apreendidas durante o curso" (ANTUNES apud

6 Edler (1999) advoga que os médicos brasileiros do século XIX praticaram a cientificidade pertinente ao período.

Movimento, Porto Alegre, v. 10, n. 3, p.53-75, setembro/dezembro de 2004 
GONDRA, 2000, p. 86). Entretanto, parece ser exatamente aí que pode ser visualizado seu valor documental. Nelas podem ser flagrados e analisados os constrangimentos institucionais que modulam a prática de sua produção, já que cumpriam um mesmo ritual e participavam de um mesmo projeto. Nesse sentido, tomálas como objeto permitiu vislumbrar"...uma pauta de preocupações em torno das quais os sujeitos [médicos] deveriam ser formados e para as quais deveriam ser construídas sensibilidades" (GONDRA, 2000, p. 85).

Nenhuma das objeções antepostas obstaculiza que as theses sejam tomadas como documentos que materializam e expressam o longo processo de escolarização, o que, portanto, amplifica sua interpelação como fim em si mesmo ao conferir-lhes a conotação de um dos registros produtores e reprodutores de sentido de um projeto de intervenção e constituição escolar. Nestes termos, ao invés de impacto, maturidade e originalidade, uma questão enfrentada no estudo foi nelas objectualizar pontos que se articulavam e davam visibilidade a temática da produção, reprodução, circulação e apropriação do conhecimento produzido, para a educação (física), a partir da Hygiene. Assim, tomadas como fontes, as theses não atestam, apenas, o que foi ou o que deveria ser a medicina - e, por meio dela, o que se expressa para a educação e para a educação física - num tempo e lugar, mas, desnaturalizadas, dão a ver disputas na construção de sentidos, para dentro e para fora, do campo médico.

Parte desta desnaturalização fez aparecer, por exemplo, que uma das características que o campo da educação física incorpora do campo médico são as práticas e representações acadêmicas das quais ele se vale para conferir importância e legitimidade aos seus objetos de disputa. A estruturação de um habitus científico, fundamental para o desenvolvimento da medicina já no século XIX, ainda errante na educação física em pleno século XXI, foi soerguida paulatinamente ao longo dos oitocentos. Esse habitus perfilou o processo de construção de uma especificidade para a educação física que configurou o engendramento do campo. A construção dessa especificidade pôde ser observada nos movimentos que marcaram a produção de sentidos e significados e estabeleceram diferenças entre o que eles médicos - nominaram inicialmente de educação physica e o que se consagrou, a partir de suas contribuições, como educação física já na virada do século XIX para o XX. É a parte desse processo que dou visibilidade a seguir.

Movimento, Porto Alegre, v. 10, n. 3, p.53-75, setembro/dezembro de 2004 


\section{Anatomia temática da educação physica oitocentista}

Como dito, as theses dão a ver constrangimentos institucionais moduladores de sentido e cunhadores de habitus. Mas, essa orquestração prática não inibia dissonâncias de opiniões. No que tange às representações delas oriundas acerca da "educação física", a sistematização fez observar que havia vários sentidos circulantes. Essa abundância sinaliza diferentes projetos em disputa, ainda no campo médico, o que convida a marcar que o pensamento médico-higienista oitocentista vislumbrava "educações físicas".

Com reordenações, foram três os principais sentidos representados e praticados quando em debate a educação physica. São eles indicações referentes: a) à conduta anterior dos pais; b) aos cuidados corporais no nascimento e na infância; e, c) ao trato das crianças em idade escolar. Vejamos.

\section{Conduta anterior dos pais}

As primeiras theses sobre educação physica escritas em meados do século XIX não eram textos escritos para incrementar o debate interno da medicina. Em vez disso, destinavam salutares conselhos $^{7}$ aos pais e futuros pais e, também, à professores.

Naquilo que se dirigia aos pais, defendia-se que os médicos deviam ser previamente consultados prevenindo-se uniões não desejáveis do ponto de vista higiênico. A possibilidade de propagação de moléstias, a falta de órgãos geradores e a detecção de um estado de perturbação ou perversão nas suas funções eram motivos para intervirem desaconselhando uniões.

Acreditava-se que o aumento da população insalubre decorria dos vícios da educação e da maneira inadequada segundo a qual se contraíam casamentos. Dentre outras alegações, os médicos insistiram para que as opções matrimoniais fossem apartadas dos negócios e desconsideradas como uma forma de arrumar as finanças, já que eram os critérios higiênicos que deveriam nortear escolhas. Esses critérios diziam respeito ao

7 Em itálico estão os termos e argumentações que tomo emprestado da escrita dos médicos estudados. Em Paiva (2003), onde dispus de espaço para explorar a construção da narrativa com abundância de citações, eles estão devidamente referenciados.

Movimento, Porto Alegre, v. 10, n. 3, p.53-75, setembro/dezembro de 2004 
estabelecimento da idade oportuna, ao cruzamento das raças e à transmissão hereditária de boas qualidades, tais como, constituição física e temperamentos. Tanto o cruzamento inter-racial - ora defendido, ora atacado - como a atenção às possibilidades hereditárias preparariam de antemão o organismo para a concepção de um bom fruto, contribuindo, assim, para a perpetuação e o aperfeiçoamento da espécie.

Outras questões recorrentes eram o celibato e seu reverso libertino, a prostituição. Notas sobre pedofilia e pederastia também se faziam presentes. Todos esses comportamentos, julgavam os médicos, predispunham à loucura. Considerava-se que "O onanismo e a prostituição concorrem para uma má educação physica, pois que impedem a conservação e propagação das boas qualidades hereditarias, e mesmo destroem-nas" (PORTUGAL, 1853, p. 9). Por isso, vários médicos viam no casamento uma saída higiênica para a consolidação da vida e a prolongação de sua duração média.

Os médicos recomendavam aos maridos não abusarem dos deveres conjugais; consumirem sóbrios alimentos; e se fortalecerem com bem regulados exercícios. Uma vez pais, deveriam pautar sua conduta com amor e austeridade numa justa medida já que "Uma vigilância excessiva e imprudente do pai diminue no filho a consciência dos proprios actos, e extingue-lhe a liberdade individual. Esta, na mocidade [precisava] ser regulada por conselhos; mas extinguil-a, [seria] crime" (ARMONDE, 1874, p. 65-66). Aos rapazes que não haviam ainda se casado era indicada a prática regular de exercícios para amainar o impulso sexual. Considerando a maturidade um período de declínio fisiológico, aos homens de meia-idade indicava-se exercícios moderados.

As (futuras) esposas recebiam muitas críticas e recomendações. A puberdade era considerada uma fase perigosa dado o abalo nervoso que a menarca imprimia ao funcionalismo dessa máquina vaidosa que eram as moças. Os médicos atribuíam ao frescor da idade a incompatibilidade com suas novas responsabilidades femininas. Em linhas gerais, era a casa o espaço destinado por eles às mulheres. Mas houve pena que se manifestasse buscando ressignificar direitos e deveres femininos. Considerava o Dr. Machado (1875, p. 14) que “...a mulher tem a liberdade de se casar ou não, que póde por uma deliberação espontanea do livre arbitrio votar-se ao celibato...". Em que pese a possibilidade - ou não - dessa escolha, as vozes médicas se somavam na constatação e censura da atitude de mulheres grávidas tentarem ocultar seu estado em nome de seus vaidosos hábitos. A prescrição médica indicava em sentido contrário recomendando que

Movimento, Porto Alegre, v. 10, n. 3, p.53-75, setembro/dezembro de 2004 
tomassem banhos mornos para evitar espasmos abortivos, usassem vestimentas leves e confortáveis, praticassem exercícios moderados, destacando-se os passeios a pé, e se fartassem de alimentos nutrientes, sem condimentos e de fácil digestão. Bebidas alcoólicas eram proibidas e aconselhava-se moderação e prudência nas familiaridades conjugais. Essas recomendações para a gravidez, e que quase sempre se estendem à vida normal, atravessam todo o período estudado.

A importância de uma prole bem constituída era tida como um compromisso social - e divino. Segundo eles, cabia à medicina, por meio da Hygiene, ensinar os pais a evitar o amontoamento de males, as exagerações de toda ordem, as influências maléficas que perturbassem a geração da prole e seus primeiros anos de vida. A família era, pois, considerada o berço de tudo: da educação e da primeira educação que era a educação physica.

Se cabe uma breve síntese, é possível dizer que os cuidados com o corpo e seu usufruto e a importância da estruturação da família na educação de seus filhos, marcam a representação dos médicos da educação physica como cuidados a serem observados na conduta estabelecida por eles para jovens e adultos.

\section{Cuidados no nascimento e na infância}

Dos cuidados destinados ao recém-nascido e à primeira infância, amamentar era o mais sagrado e sublime dever negligenciado pelas mães. Os médicos fizeram campanha maciça para que elas assumissem essa responsabilidade. Eram temas recorrentes a essa discussão a impossibilidade de amamentação por paixões violentas, predisposição à cólera ou à embriaguez; o estabelecimento de critérios para escolha de uma ama de leite; o aleitamento artificial com leite de vaca ou de cabra. O desmame era a preocupação subseqüente, acrescida da prescrição da dieta (com papas e frutas) na qual as crianças deveriam ser introduzidas.

Outro cuidado em pauta eram as orientações para a higienização do recém-nato e da criança que diziam respeito a recomendações com o cordão umbilical, cuidados com o primeiro e demais banhos. Destaque era dado à temperatura da água que deveria ser morna - e a evitação de misturar qualquer substância (vinhos, licores, óleos) a ela. Além disso, execravam as amarrações, cueiros e cintas que impediam os movimentos e dificultavam a respiração e a circulação do recém-nato.

Cuidados e prudência, circunspecção nas práticas ditadas pelas regras da Hygiene, boa alimentação, liberdade para se 
movimentar e amor eram os principais conselhos dados aos pais para educar seus filhos. Esses conselhos, com pequenas modificações, se estendiam pela primeira fase da segunda infância.

Os temas alimentação geral, incluindo discussão de bebidas, e os cuidados com o asseio corporal adentram as recomendações destinadas à escola. Creio ser suficiente marcar que os médicos recomendavam para as crianças - em idade escolar e antes disso - uma alimentação variada, sem o abuso de condimentos. As bebidas indicadas eram bastante água; chá e café, com moderação. A alimentação era importante, dentre outros fatores, porque se prestava a modificar os temperamentos, assim como os banhos.

Mais especificamente ligados à primeira infância eram os cuidados exigidos com a temperatura ambiente, já que se considerava que o clima tinha um grande poderio sobre o corpo e sobre a moral. Recém-nascidos e crianças não deveriam ser submetidos a mudanças bruscas de atmosphera, embora, com moderação, deveriam aprender a enfrentar o frio sem excesso de roupas. Lembra o Dr. Ubatuba (1845, p. 15) que "Muito mais convem, que os meninos se aqueçam pelo exercicio do que pelas vestimentas, pois é com a liberdade e com os movimentos que elles se desenvolverão".

Mas, havia que se considerar as leis que presidem certos movimentos. Por exemplo, era "prejudicial forçar-se o menino a andar mui cedo, o que [podia] viciar debeis membros que ainda não [tinham] força para sustentarem o peso do corpo" (UBATUBA, 1845, p. 18). Na fase do engatinhar, “...os exercicios aconselhados [...] consistem quasi que só no auxilio que se [...] deve prestar [a criança] para o desenvolvimento dos seus membros, principalmente os da locomoção" (MIRANDA, 1892, p. 5). Quando começasse a andar, os cuidados aumentariam para que a criança não andasse depressa. Ao sugerirem que "...pouco a pouco a [...] acção [muscular] tornava-se mais energica e mais precisa" (MACHADO, 1875, p. 23), os médicos mostravam a seus leitores a noção de progressividade dos esquemas motores.

Veremos mais à frente que a necessidade de movimento da criança (na escola) foi cada vez mais justificada pela fisiologia. Também para a infância procurou-se argumentar nesse sentido. Assim, o Dr. Machado (1875, p. 23) acenava que a ação provocada pelos vários movimentos feitos pelas crianças tinha por função “desinvolver o aparelho muscular, facilitar a circulação do sangue,

Movimento, Porto Alegre, v. 10, n. 3, p.53-75, setembro/dezembro de 2004 
activar as combustões intersticiaes, emfim concorrer directamente para o jogo physiologico do organismo". Por isso, explicava, o colo deveria ser evitado deixando que as crianças pequenas se entregassem livremente aos seus movimentos naturais e as maiores aos seus ruidosos folguedos, que poderiam ser dirigidos por adultos, mas nunca impedidos. Mas, se a movimentação era uma necessidade infantil, o repouso, também. O dia deveria ser dedicado para atividades; a noite, ao sono. A inversão dessa ordem deterioraria os sentidos, a saúde, o temperamento.

Outro tema que mais especificamente se ligava aos cuidados destinados aos recém-nascidos e à primeira infância era a preocupação dos médicos em evidenciar para os pais características da evolução orgânica. Nas primeiras theses sobre educação physica, a ênfase recaía sobre o desenvolvimento dos bebês e das crianças. Descreviam-se condutas que caracterizavam os primeiros dias e os primeiros meses de vida num esboço daquilo que hoje nominaríamos de desenvolvimento motor.

No que se refere à adequação de movimentos, consideravase que a movimentação corporal produzia vigor e, nessa fase da vida, de maneira muito especial. Portanto, as brincadeiras e correrias deveriam ser toleradas e mesmo incentivadas porque “...esses jogos em que os meninos passam os mais alegres momentos de sua edade, tambem disfarçam o meio de obrigalos ao exercício, o que alguns paes querem prohibir, deslembrados do quanto elles são gostosos, e que é delles que os meninos receberao a saude e o vigor" (UBATUBA, 1845, p. 16).

Os médicos representaram os cuidados com a educação physica na infância resumidos às seguintes indicações: passeios ao ar livre, exposição ao sol, habitação no campo, alimentação sem exageros, banhos frios e movimento. Muito movimento. Inspirados em Rousseau, o lema era repetir ações no e com o corpo. Assim, a educação higiênica investia na incorporação de hábitos proveitosos e na exorcização dos danosos. Muitas das rotinas higiênicas de uma educação physica infantil se prolongam e se complexificam nas prescrições destinadas à criança em idade escolar.

\section{Trato da criança em idade escolar}

A educação impetrada em estabelecimentos específicos representava um evento sociocultural que redividia a vida biocro-

Movimento, Porto Alegre, v. 10, n. 3, p.53-75, setembro/dezembro de 2004 
nológica dos meninos. Ela era representada como uma reordenação brusca do curso da infância. As casas de educação tinham um papel de peso no projeto de educação integral traçado pelos médicos por potencialmente aglutinarem condições necessárias para um tipo de socialização que julgavam (mais) civilizado. O trabalho que a maioria dessas casas desenvolvia até então era considerado desolador e, com as armas que dispunham - a produção, reprodução e circulação do conhecimento -, procuraram intervir na economia funcional desses estabelecimentos, almejando transformá-los em escolas nas quais se ensinasse o elementar (e isso não era pouco na consideração dos médicos) para uma vida digna.

A Hygiene julgava conhecer meios, transformados em regras higiênicas, que pudessem alterar as práticas educacionais vigentes, maximizando o potencial educativo e propriamente escolar desses estabelecimentos. Na pauta permaneciam os seguintes assuntos para tratar da educação physica dos meninos quando esta deixava de ser responsabilidade direta da mãe para se tornar a de um diretor: asseio, vestimentas, alimentação e uso de bebidas, mudanças morfológicas e orgânicas. Aos cuidados mais diretos de uma higiene pessoal agregaram-se cuidados de uma higiene institucional dirigida à melhora da educação (escolar) sistematizada.

Além disso, incorporaram novos temas como o debate da educação popular, da educação feminina e da co-educação. Discutia-se a educação institucionalizada em questões que iam da localização dos prédios escolares e sua insalubridade até sugestões e conselhos sobre como organizar o tempo, o espaço, os materiais e os saberes escolares. Os médicos desqualificavam os castigos corporais como meio de educação, explicavam as paixões e a forma de contorná-las e combatê-las, abominavam a prática da masturbação e apresentavam a ginástica como panacéia para prevenção ou cura, conforme o caso. Aliás, a ginástica era tida como excelente formadora de hábitos na educação physica dos meninos, colaboradora na formação de hábitos higiênicos, não sendo ela, entretanto, a única forma de exercitação aconselhada. Os médicos recorriam a uma gama de práticas corporais para esse fim. Canto e declamação são representados como exercícios moderados e higiênicos. Mas, sempre que pretendiam demonstrar a eficiência física e moral da educação physica, recorriam à exercitação metódica e sistematizada, isto é, à ginástica, para dar-lhe legitimidade. Além

Movimento, Porto Alegre, v. 10, n. 3, p.53-75, setembro/dezembro de 2004 
disso, reconheciam sua importância na aclimatação e na temperança do comportamento. Paulatinamente, com maior precisão, explicavam seus efeitos fisiológicos, sem menosprezar seus efeitos disciplinares e moralizantes. Dentre esses tantos assuntos, neste texto, destaco apenas alguns dos comentários que se prestam à observação do processo de escolarização da educação physica.

A degeneração era um tema em pauta sob vários aspectos e o estragamento da mocidade que iria construir a nação brasileira era condenável qualquer que fosse o motivo. Diretores mercenários eram chamados à responsabilidade no seu importante papel de formadores da juventude (robusta) a ser colocada à disposição da sociedade.

Uma educação viciada - comercialmente triunfante, higienicamente desvirtuada -, ao invés de formar cidadãos que poderiam prestar serviços à sociedade, formaria adultos que herdariam seus males e os transmitiriam aos seus filhos. Os médicos sabiam que a educação era uma questão política e social e, por isso, buscaram influenciar legisladores, rogando que seus conselhos fossem por eles levados em conta.

$\mathrm{Na}$ década de 1870, reivindicou-se, enfaticamente, a sistematização da educação escolarizada como conseqüência de uma organização política. Família e Estado assumiriam suas obrigações na edificação do monumento da civilização somando esforços para a popularização da educação. Os médicos identificavam que um grande obstáculo se interpunha a esse projeto: a centralização de esforços na Corte, que concentrava os principais estabelecimentos de ensino. Entretanto, reconhecem, nem mesmo a centralização aquebrantava o elevado algarismo dos analfabetos. O sistema de ensino parecia precisar de reforma e um dos meios apontados pelos médicos para viabilizála era incentivar a criação de boas escolas em todas as províncias do Império.

Outra abordagem da questão da degeneração enfocava a educação da mulher, fosse porque ela não se disseminara em instituições próprias, fosse porque nessas instituições ela não se procedesse no molde autorizado pela Hygiene. Não esqueçamos: mulheres mal educadas, que só se ocupassem com futilidades, e não instruídas, poderiam arruinar a educação (physica) de seus filhos. Além do que, alguns médicos consideravam a negação à mulher do direito de estudar também uma forma de estragar a mocidade. A questão era comumente debatida de modo conservador, mas, as theses do Dr Armonde e do Dr. Machado, romperam com a representação corrente de ser a mulher intelectualmente inferior ao homem e que muita

Movimento, Porto Alegre, v. 10, n. 3, p.53-75, setembro/dezembro de 2004 
instrução era-lhes prejudicial por poder arrastá-las à perdição. Propunham que ambos os sexos tivessem o mesmo direito à educação, à educação physica e ousavam propor a co-educação.

Pois bem, quando o assunto era escola, os médicos são unânimes em avaliar que a educação vai mal nos estabelecimentos especificamente destinados para esse fim. Os motivos são muitos e muitas são as sugestões higiênicas a serem adotadas para que o quadro se tornasse um pouco mais alentador. Havia uma grande preocupação em estabelecer as condições materiais e subjetivas necessárias para o desenvolvimento de uma educação physica própria às casas de educação. Discutia-se amplamente a localização dos prédios escolares e sua insalubridade, além de sugestões e conselhos para organizar o espaço, o tempo, os materiais e os saberes escolares.

As casas de educação garantiriam salubridade sendo suficientemente espaçosas, arejadas, claras e construídas em terrenos secos para que não contribuíssem com a proliferação de miasmas. Deveriam possuir capacidade espacial proporcional ao número de alunos que atendessem. Nas theses médicas, a preocupação com a racionalização dos espaços e dos tempos escolares é constante, também devido às formas de convívio que propiciavam. O contato com a família é colocado em xeque. Uns advogavam a favor do regime de internato; outros, do regime de externato, julgando o primeiro funesto para o desenvolvimento físico e moral da criança.

Nesse contexto, cabia-lhes a crítica para que o regime de internato fosse melhorado. Tal representação parece se atrelar à necessidade de se produzir a legitimidade da escola como lugar de direito da educação formal. Entretanto, conforme esse sentido vai se sedimentando o regime de externato passa a ser privilegiado. Não se descartava, contudo, a representação de que a família também deveria ser educada. Lembremo-nos que os conselhos destinados aos pais são freqüentes.

O tempo escolar também era questionado em relação a sua seriação. Era um problema manter juntos meninos de idades e interesses diferenciados, assim como submete-los a extenuantes horas de estudo.

Uma outra questão era a atenção a ser dada à materialidade das práticas escolares. Considerava-se, por exemplo, que os móveis influiam no desenvolvimento físico dos educandos. Para que se pudesse exigir atitudes de higiene e a polidez recomendada, era preciso que a escola dispusesse de bancos com encosto, como os modernos

Movimento, Porto Alegre, v. 10, n. 3, p.53-75, setembro/dezembro de 2004 
móveis americanos, ao invés dos toscos bancos onde não se tinha onde apoiar o tronco e nos quais os alunos eram obrigados a conservar-se sentados por longas horas do dia. Lousas e vidros quebrados, mapas rotos, riscos e figurinhas nas paredes, as mesas sujas e carcomidas deveriam ser evitados pois falta de recursos e asseio não eram incompatíveis. Em nome da civilização, era preciso higienizar a pobreza, tratando com zelo o ambiente escolar e seus materiais. Essa era uma forma de promover educação physica. A escola era o lugar mais propício ao desenvolvimento da educação integral - physica, moral e intelectual - e, por isso, os médicos buscaram projetá-la - no duplo sentido - como digna dessa missão. Um dos seus esforços consistia na tradução que esses ramos da educação poderiam comportar em termos de saberes escolarizáveis e escolarizados, traduzidos em conteúdos que foram mapeados cuidadosamente por Gondra (2000). Esse autor nos chama atenção para o fato de que

Aintervençãonocorpoeanecessidade de promovê-la constituiu-seemum consenso nas teses examinadas, havendo uma pequena variação referente ao modo como esta deveria ocorrer em relação às demais dimensões: as intelectuais e as morais. Para uns, o início de toda formação humana dava-se na/pela educação do corpo. Para outros, a hierarquia não encontrava-se posta nestes termos, tratando-se ademais de uma intervenção global na formação do homem e, neste sentido, deveria ocorrer de forma consorciada. Entretanto, mesmo os que defendiam uma hierarquização nas intervenções também estavam convencidos de que, num determinado momento tais dimensões encontravam-se associadas. (GONDRA, 2000, p. 254)

Esse momento era quando ingressavam na educação escolarizada. Ainda com relação à intervenção higiênico-pedagógica sobre o corpo, via educação physica, vale frisar que esta se dava em cuidados diversos, bem como com práticas corporais especificamente pinçadas da cultura corporal de movimento. Por ora importa frisar que, para os médicos, eram íntimas as relações estabelecidas entre a tríplice ramificação da educação, jáque muitas questốes não poderiam ser completamenteclassificadas em um ramo, por se ligarem igualmente aos outros. Arrisco um breve esboço dos consórcios percebidos e/ou produzidos pelos médicos na interface desses diferentes ramos. De maneira geral, acreditava-se que

Não [era] somente a educação scientifica que [merecia] cuidado [na escola]; a educação physica [deveria ser] ali convenientemente dirigida, a gymnastica e as bellas artes [eram] parte importates da educação, desenvolvendo o corpo e corrigindo as naturezas asperas; o sentimento do bello, do justo, e do honesto [deveria ser] inoculado na mocidade pelo complexo dos differentes ramos de ensino (COUTINHO, 1857, p. 9).

Movimento, Porto Alegre, v. 10, n. 3, p.53-75, setembro/dezembro de 2004 
Os novos conhecimentos, muito mais amplos que o até então tradicional ler, escrever e contar, exigiam que os métodos de ensino das primeiras letras se tornassem atraentes e divertidos. Observei que, em pelo menos três sentidos, os médicos perspectivavam que a educação physica poderia interagir com a educação intelectual: de modo preparatório, moldando o corpo e as vontades - de forma a predispô-lo à disciplina escolar; de modo compensatório, servindo como tempo de recreio para as árduas atividades intelectuais; e, numa certa inserção "metodológica", chamando a atenção dos professores para a importância do "lúdico" no desendurecimento de suas atividades didáticas.

Educação physica e educação moral se entrelaçaram e se misturaram nesse projeto de educação integral, ora numa perspectiva inibidora e limitante, ora liberalizante. O direito à livre escolha, à liberdade de poder escutar a voz esclarecida da razão, introduzia novidades que perpassavam novas proposições metódicas para o ensino e, também, novas condutas para fazer incorporar condutas.

A educação moral procedia, em parte, da educação religiosa. Ateísmo e superstição eram práticas funestas e levavam à degeneração moral. Mas, também encontramos médicos que, sem descuidar de uma formação cristã, colocavam o peso da educação moral na família. O sentimento de justiça deveria ser despertado e desenvolvido em casa e na escola, o que fazia com que os castigos escolares se colocassem como um problema para os médicos. Houve quem os defendesse, mas a maioria preferia apontar um outro caminho que não envolvia a violência física, sendo tolerados quando o que contava era o constrangimento e a coação.

A ginástica, certamente, mas, principalmente, os jogos ofereciam préstimos à saúde moral edificando o caráter por meio de um mover-se alegre e estimulante. Apresentavam a vantagem de combinar leis do jogo com leis sociais: subordinavam o movimento a regras, disciplinavam a atividade individual e coletiva, moldavam as deliberações, responsabilizavam o proceder de cada um, fortaleciam laços de solidariedade.

Os médicos opinavam sobre castigos argumentando que não eram de grande vantagem. Deveriam ser banidos das práticas escolares, porque “...o estimulo da dôr physica é tão duradouro como a sensação que produz: a correção moral feita com discernimento

Movimento, Porto Alegre, v. 10, n. 3, p.53-75, setembro/dezembro de 2004 
desperta a consciencia e a alma" (COUTINHO, 1857, p. 20-21). Acreditava-se que, quando um diretor conseguia estabelecer a obediência com base no temor, a educação já estaria corrompida. No fim do século, a necessidade desses castigos parece estar totalmente abolida, pelo menos em tese, pela frenologia. ${ }^{8}$

Se os castigos eram abominados quando decorrentes da desordem provocada pela privação da liberdade de movimento, eram considerados reprimenda válida, ainda que como último recurso, quando o motivo era o onanismo. Acreditavam os médicos que corações malformados tinham propensão a desenvolver paixões: o ódio, a cólera, a vingança, o erotismo, a gula, entre outras. A educação moral é que poderia afastá-las, contê-las, modificálas. Mas nenhuma paixão foi tão explorada e temida pela educação como a do onanismo. Seu trato evidenciava como a educação moral e a physica poderiam ser transformadas num quase mesmo fenômeno, já que a ginástica era apresentada como panacéia para prevenção ou cura, conforme o caso.

Para evitar a situação, os exercícios ginásticos deviam ocupar todo o tempo de recreação dos meninos dada a benéfica interferência que poderiam promover na constituição física e preparando-os para um sono reparador. Previam, também, a possibilidade deles serem úteis como meio terapêutico. O essencial era habituar os meninos a uma vida ativa e dura, para o que concorria a ginástica. Os exercícios corporais, para alguns médicos, constituiam a base da educação da mocidade.

Mas, não era qualquer ginástica que merecia ser qualificada como escolar. Escolarizável e escolarizada era a ginástica racional e não a de saltimbancos, perigosa e imoral, capaz de deteriorar em pouco tempo robustas constituições. A recomendação era reserva, por parte de pais e de diretores, em relação àquelas ginásticas que demandavam o uso de instrumentos e aparelhos.

Os médicos julgavam que a educação physica, principalmente no que tange à prática de exercícios, fora abandonada pelos pais e nos estabelecimentos de ensino uma vez que, nesses últimos, era tida como inútil e prejudicial. Alegava-se, por parte dos diretores e segundo os médicos, que eles roubavam um "...tempo que seria mais proveitosamente applicado á cultura do espirito" (MACHADO, 1875, p. 46). Entretanto, consideravam que a

8 Sumariamente, acreditava-se que as qualidades humanas derivavam do desenvolvimento e da atividade dos órgãos ao passo que os defeitos eram resultado da não atividade e/ou da pequenez (de uma das partes) do cérebro.

Movimento, Porto Alegre, v. 10, n. 3, p.53-75, setembro/dezembro de 2004 
educação que se centrava somente no desenvolvimento do espírito era prejudicial porque corroborava a degeneração física da mocidade.

A ginástica não era, entretanto, a única forma de exercitação aconselhada para crianças e jovens. Os médicos recorriam a uma variada gama de práticas corporais,

... a marcha, o salto, a dansa, a carreira, a natação, a esgrima, e os diversos jogos,
em que se executam movimentos do corpo, e braço, como a malha, a bolla, podem
ser empregados com vantagem. A equitação, e a luta entrão igualmente no
numero dos exercicios, que se podem practicar (MELLO, 1846, p. 35).

Ignoradas pelas casas de educação, sugeria-se que as caminhadas deveriam ser adotadas ao menos duas vezes por semana. Esses exercícios, feitos na forma de passeios, teriam a vantagem de distrair os espíritos dos labores da inteligência e livrar-lhes da reclusão e da inércia tão propícias ao afloramento de prazeres eróticos. Apenas na última década do século XIX, a ginástica sueca é apresentada com entusiasmo. E, nela, influenciado pelo argumento spenceriano e pela forma como os franceses buscavam se apropriar da prática da ginástica, o Dr. Brito (1892) enfatizava uma outra maneira de sistematizar atividades corpóreas: os jogos dirigidos ganhavam centralidade pedagógica na ginástica.

Mas havia práticas corporais que não eram recomendadas. Caça, equitação, bilhar, vectação são destacados porque, apesar das contribuições que podem trazer à exercitação do corpo, têm também suas inconveniências e porque não se prestam aos fins escolares. Estabelece-se, então, uma distinção entre as práticas corporais que poderiam e/ou deveriam ser escolarizáveis e as que não. A idéia de utilidade, facilidade de ensino, proporcionamento da formação de um bom coração parece estar entre os critérios evocados. A capoeira era nociva, um ente que chegava a comprometer a civilização brasileira, muito embora fosse notório que ela era praticada com(o) paixão pelos meninos que freqüentavam as escolas públicas.

Em síntese, ginástica, natação, dança, jogos e canto são exercícios corporais autorizados pela medicina que deveriam ser praticados desde a infância para que pudessem contribuir com a educação physica da mocidade. Além de influir no crescimento e desenvolvimento dos corpos, tinham outras propriedades higiênicas.

Movimento, Porto Alegre, v. 10, n. 3, p.53-75, setembro/dezembro de 2004 


\section{Notas sobre a produção da legitimidade}

É de se observar que, todas as vezes que os médicos queriam demonstrar pormenorizadamente a eficiência física e moral da educação physica, recorriam à exercitação metódica e sistematizada da ginástica.

Do ponto de vista pedagógico, os médicos reconheciam sua importância como prática integrante dos processos de uma educação physica por atribuir-lhe possibilidades construtivas de valores múltiplos. Como bem se expressara o Dr. Ubatuba (1845, p. 17), "o exercicio bem longe de deminuir a intelligencia, a augmenta, talvez porque o corpo se preste como melhor instrumento [da educação]".

Mas, os médicos também reconheciam a importância da exercitação metódica e sistematizada a partir do ponto de vista orgânico que significava, apesar das variações argumentativas, mostrar o valor higiênico da ativação e regularização das funções vitais. Consideravam que os exercícios físicos eram um tônico de poderes estimulantes capaz de conservar e melhorar a saúde. A única situação no período estudado na qual aparecem unanimamente com função terapêutica é na representação de que eles eram capazes de curar os meninos da paixão pelo onanismo. Somente no fim do século XIX, a abordagem terapêutica dos exercícios - especificamente os ginásticos - apareceu ressaltada, ora ligada a doenças, como o raquitismo, a obesidade, a gota, a diabetes e algumas lesões cardíacas, ora deliberadamente transformada em kinesiterapia - a arte de curar pela sistematização dos movimentos.

O que é preciso marcar é que a questão da legitimação da prática de exercícios com base na sua contribuição orgânica tem sua ênfase na teoria dos temperamentos. Acreditava-se que a prática da ginástica e demais exercícios físicos poderia neles influir e mesmo corrigi-los, ${ }^{9}$ transformando temperamentos linfáticos e nervosos em sangüíneos. Os dois primeiros se colocavam como problemas para as casas de educação dada a minúcia de cuidados que exigiam. Os diretores, com sorte,

9 Em síntese, a teoria dos temperamentos reconhecia a universalidade de três tipos: o sangüíneo (caracterizado pela regularidade de todas as funções vitais, o mais higiênico dos temperamentos), o linfático (tendente à obesidade e o menos higiênico dos temperamentos) e o nervoso (caracterizado pela irregularidade de todas as funções, compleição magra e músculos pouco desenvolvidos).

Movimento, Porto Alegre, v. 10, n. 3, p.53-75, setembro/dezembro de 2004 
poderiam revertê-los seguindo as recomendações higiênicas dos exercícios, da alimentação, do banho.

Mas a tese da benignidade da prática dos exercícios físicos com base na teoria dos temperamentos nem sempre parece ter sido endossada. O Dr. Naegeli (1863, p. 3), em sua these de revalidação de diploma expedido pela Universidade de Zurich, reordenava o sentido do debate higiênico e colocando-o numa rota mais próxima à Fisiologia, disciplina cada vez mais em evidência na segunda metade do século XIX na produção do conhecimento médico:

...Todos os homens inteligentes, facilmente se convencem da utilidade dos exercicios do corpo em geral, mas a maior parte acham-nos praticaveis sómente em paizes frios e temperados e poem em duvida não só suas vantagens para os habitantes das regiões tropicaes, como mesmo pretendem provar a sua nocividade absoluta nessas regiões.

Com essa formulação, o Dr. Naegeli colocava a prática da ginástica em debate enfrentando a questão a partir da discussão típica de um dos assuntos mais prestigiados em Hygiene: a controvérsia entre aclimatamento e aclimatação. ${ }^{10}$ A tese central sustentada por ele é que a ginástica seria um poderoso agente da aclimatação, refutando a hipótese da inadequabilidade da prática metódica de exercícios no clima tropical.

O destaque que deve ser feito à argumentação do Dr. Naegeli é que, nas theses analisadas, ele, e só ele, se preocupou em demonstrar num trançado sui generis dos conhecimentos da Fisiologia com os da Hygiene a centralidade argumentativa legitimadora da prática da ginástica - a forma como atuava na economia animal. Apenas disso se ocupou, tomando como dada, em virtude da sua própria argumentação, a importância da educação physica da mocidade.

Os médicos brasileiros percorriam um caminho inverso na estruturação de suas argumentações. Eram extensivos na explanação das questões afetas à educação (physica), buscando ser taxativos nas suas prescrições higiênicas para solucionar os problemas a ela(s) pertinentes e mais sucintos na sua argumentação anatomofisiológica.

10 Edler (1999, p. 80) explica a aclimatamento e aclimatação: "O primeiro referia-se ao processo natural de adaptação do indivíduo a um clima diferente do habitual, decorrente da ação do meio sobre a economia humana. $\mathrm{O}$ segundo indica os procedimentos higiênicos mobilizados para estabelecer um novo equilíbrio entre o organismo humano e o clima circundante".

Movimento, Porto Alegre, v. 10, n. 3, p.53-75, setembro/dezembro de 2004 
Paulatinamente, essa explicação se complexificava com os avanços e descobertas no plano da Fisiologia, mas o espaço para a discussão educacional sempre foi o privilegiado nas theses.

Mas, se os médicos concordavam, ainda que variando a densidade, a complexidade e a origem teórica de seus argumentos, sobre o caráter benéfico da prática de exercícios, havia uma situação em que eles eram deliberadamente rechaçados: quando da sua prática excessiva. Destarte essa observação, o peso da argumentação médica incide na tese da begnidade da prática da exercitação física metódica, tanto do ponto de vista orgânico como pedagógico. Contudo, mesmo diante de seus irrefutáveis argumentos não sabiam “...que especie de desculpa procurar para os nossos collegios publicos e particulares onde a gymnastica é devotada ao mais completo despreso" (GUIMARÃES, 1858, p. 43).

\section{Síntese provisória}

Foi possível notar que, majoritariamente, quando os médicos falavam dos benefícios orgânicos, estes apareciam arrematados com demais benefícios intelectuais e morais. Uma certa cisão entre eles só foi por mim observada ao final do século, quando o argumento fisiológico da melhora das funções vitais parece ganhar fôlego com os novos conhecimentos forjados em experiências de laboratório. Essa distinção implica uma reordenação: argumentar a favor de uma educação physica vai tomando o rumo de se explicar e fundamentar a ação propriamente fisiológica (tal como o termo pode ser entendido hoje) dos exercícios do/no corpo, tanto é que, na these do Dr. Lima Filho, defendida em 1907, falar de "A educação physica moderna" já era somente falar das ginásticas autorizadas e escolarizadas, isto é, aquelas desenvolvidas, metodizadas e consagradas na Alemanha, na França, na Suécia, tal como acenavam o Dr. Miranda e o Dr. Brito, no final do século XIX.

O esporte também era discutido já que instituído como prática corporal legitimada e consagrada na Inglaterra. Assim, vemos que, na produção do conhecimento médico, vai-se demarcando um outro patamar de intervenção deste conhecimento na "educação física", qual seja, aquele que passa a ter o poder de designar como (sistematização "científica", isto é, fisiológica e pedagógica da prática que compõe o método) e por que (benefícios testados e atestados na economia animal) o corpo deve se exercitar. Questões mais gerais, que diziam respeito

Movimento, Porto Alegre, v. 10, n. 3, p.53-75, setembro/dezembro de 2004 
às matérias de Hygiene e às relações estabelecidas entre elas e a educação physica pelos médicos brasileiros deixam seus resquícios, mas declinam como centro da argumentação.

Os tratos com o recém-nato, aleitamento, cuidados na gravidez e na escolha dos pares matrimoniais parecem ter sido temáticas que, ao longo dos anos, ganharam vida própria em outras disciplinas, tais como, Partos, moléstias de mulheres pejadas e paridas, e de crianças recém-nascidas e, mais à frente, na discussão da Puericultura e da Obstetrícia. A questão do casamento, do cruzamento das raças e sua possível "depuração", foi se colocando como uma saída para a construção da brasilidade, mas, também, como um abismo, que mobilizou, nas décadas iniciais do século XX, violentas discussões acerca da eugenia. Essa ciência do aperfeiçoamento racial perpassou assumida ou rejeitada - projetos para consolidação da nação e não foi privilégio dos médicos o seu estudo, sua defesa ou refutação. Entretanto, o debate higiênico e eugênico se agudizava rápid̉a e densamente naquela época, dada a sua complexidade e capacidade de organização e reordenação. ${ }^{11}$ Questões afetas à relação meio ambiente e construção de escola talvez tenham migrado para a pauta dos engenheiros higienistas que se puseram a urbanizar as cidades brasileiras na virada do século. ${ }^{12}$

Da mesma maneira que foi viável observar nas theses as diferentes entradas cunhadas para abordar a temática da "educação física", também foi possível perceber os caminhos singulares em que os médicos produziram e veicularam representações e práticas uníssonas. Havia opiniões e argumentos comuns sustentados por eles, ao longo dos anos, quando o assunto era educação, "educação física" e ginástica. Esses caminhos singulares dizem respeito a três idéias-força expressas, a saber, nas representações de: a) uma educação (escolar) obrando a construção da nação, b) uma educação que aos poucos tornava inevitável e imprescindível para o projeto civilizatório a implementação e efetivação da escolarização da educação e c) de uma educação para a saúde (coletiva e individual), gestada no, com e para o corpo (robustecido). Esse traço regular também corroborou com a tessitura da especificidade geradora do campo da educação física, mas só será possível abordá-lo em outra oportunidade.

11 Sobre a heterogeneidade do movimento higienista, consultar Góis Junior (2000). 120 estudo de Coelho (1999) mostra que a engenharia foi a terceira das três grandes 120 estudo de Coelho (1999) mostra que a engenharia foi a terceira das três grandes
profissões imperiais a se organizar (as outras, a medicina e advocacia). Questões profissões imperiais a se organizar (as outras, a medicina e advocacia). Questões
técnico-ambientais eram de jurisdição médica, por meio da Higiene. Por volta da década de 1870, a engenharia se hasteava neste território vinculando a profissão aos temas do saneamento e da higiene pública, acrescentando-lhes charme da estética urbana.

Movimento, Porto Alegre, v. 10, n. 3, p.53-75, setembro/dezembro de 2004 
Contribuiciones de la Hygiene a la escolarización - de la Educación Fisica

Resumen: Explora parte de la argumentación construida por Paiva (2003) en la demonstración de la centralidad del proceso de escolarización en la creación de las condiciones de posibilidad para el engendramiento del campo de la educación física en Brasil. Presenta, categoriza y analiza representaciones y practicas medico-higienistas difundidas en la producción del conocimiento sobre y para la educación física, teniendo como fuentes las tesis sostenidas en la Facultad de Medicina de Rio de Janeiro, en el siglo XIX.

Palabras-clave: Pensamiento Medico-higienista del Siglo XIX, Historia de la Educación Física en Brasil, Escolarización.

Hygiene contributions to schooling in Physical
Education
Abstract: This present paper explorer part of the
argumentation proposed by Paiva (2003) on the
demonstration of the schooling process centralization
in the creation of possible conditions to the
engenderment of physical education field in Brasil. It
introduces categorizes and analyses the representations
and practices of the medical-hygiene entailed to the
prodution of Knowledge concerning physical
education. The sources of this paper are the thesis
substantiated at the College of Medicine of Rio de Ja-
neiro, in the nineteenth century.
Keywords: Eight Hundred Thought Medical-hygiene,
the History of Physical Education in Brazil, Schooling.

\section{Referências}

ARMONDE, Amaro Ferreira das Neves. Da educação physica, intellectual e moral da mocidade do Rio de Janeiro e de sua influencia sobre a saude. Rio de Janeiro: Typographia do Apostolo. 1874.

BOURDIEU, Pierre. A economia das trocas simbólicas. São Paulo: Perspectiva, 1987.

BRITO, Severino de Sá. Educação physica. Rio de Janeiro: Imprensa Mont'Alverne-Ferreira \& C, 1892.

CASTELLANI FILHO, Lino. Educação física no Brasil: a história que não se conta. Campinas: Papirus, 1988.

Movimento, Porto Alegre, v. 10, n. 3, p.53-75, setembro/dezembro de 2004 
CHERVEL, André. A história das disciplinas escolares: reflexões sobre um campo de pesquisa. Teoria e educação, Porto Alegre, n. 2, 1990, p. 177-229.

COELHO, Edmundo Campos. As profissões imperiais: medicina, engenharia e advocacia no Rio de Janeiro 1822-1930. Rio de Janeiro/São Paulo: Record, 1999.

COUTINHO, Candido Teixeira de Azeredo. Esboço de uma hygiene dos collegios applicavel aos nossos: regras principaes tendentes a conservação da saude e do desenvolvimento das forças physicas e intellectuaes segundo as quaes se devem regular os nossos collegios. Rio de Janeiro: Typographia Universal de Laemmert. 1857.

EDLER, Flávio Coelho. A constituição da medicina tropical no Brasil oitocentista: da climatologia à parasitologia médica. $251 \mathrm{f}$. Tese (Doutorado em Saúde Coletiva) - Programa de Pós-Graduação em Saúde Coletiva, Universidade Estadual do Rio de Janeiro, Rio de Janeiro, 1999.

FARIA FILHO, Luciano Mendes. Instrução elementar no século XIX. In: LOPES, Eliane Marta Teixeira; FARIA FILHO, Luciano Mendes; VEIGA, Cynthia Greive. (Orgs.). 500 anos de educação no Brasil. Belo Horizonte: Autêntica. 2000b. p. 135-150.

GÓIS JUNIOR, Edivaldo. Os higienistas e a educação física: a história dos seus ideais. 2000. 178 f. Dissertação (Mestrado em Educação Física) - Programa de Pós-Graduação em Educação Física, Universidade Gama Filho, Rio de Janeiro, 2000b.

GONDRA, José Gonçalves. Artes de civilizar: medicina, higiene e educação escolar na Corte Imperial. 2000. 475f. Tese (Doutorado em Educação) Programa de Pós-Graduação em Educação, Universidade de São Paulo, São Paulo, 2000.

GUIMARÃES, Antenor Augusto Ribeiro. A hygiene dos collegios. Rio de Janeiro: Typographia Imparcial de J.M. Nunes Garcia. 1858.

MACHADO, João da Matta. Educação physica, moral e intellectual da mocidade do Rio de Janeiro e de sua influencia sobre a saude. Rio de Janeiro: Typographia de G. Leuzinger \& Filhos. 1875

MIRANDA, Rogério Corrêa de. Da kinésiotherapia. Rio de Janeiro: Luiz Macedo, 1892.

MELLO, Joaquim Pedro de. Generalidades acerca da educação physica dos meninos. Rio de Janeiro: Typographia de Teixeira e comp. 1846.

NAEGELI, Wilhelm. A utilidade dos exercicios gymnasticos nos paizes tropicaes. Rio de Janeiro: Typographia Perseverança. 1863. (Tese apresentada à FMRJ a fim de poder exercer a profissão no Imperio do Brazil/Doutor em medicina pela Universidade de Zurich). 1863.

PAIVA, Fernanda Simone Lopes de. Artes de civilizar: medicina, higiene e educação escolar na Corte Imperial. 2000. 475f. Tese (Doutorado em Educação) - Programa de Pós-Graduação em Educação, Universidade de São Paulo, São Paulo, 2000

PORTUGAL, Antonio Nunes de Gouvêa. Influencia da educação physica do homem. Rio de Janeiro: Typographia Universal de Laemmert. 1853.

UBATUBA, Manoel Pereira da Silva. Algumas considerações sobre educação physica. Nicteroy: Typographia Commercial de E. C. dos Santos. 1845.

Movimento, Porto Alegre, v. 10, n. 3, p.53-75, setembro/dezembro de 2004 
Recebido em: 09/09/2004

Aprovado em: 25/10/2004

Fernanda Simone Lopes de Paiva

$$
\text { Caixa Postal } 019014
$$

29.060-970 - Vitória/ES feepaiva@hotmail.com

Movimento, Porto Alegre, v. 10, n. 3, p.53-75, setembro/dezembro de 2004 